\title{
Sombreamento na produção inicial de hastes florais de Strelitzia reginae em Acorizal, $\mathbf{M T}^{(1)}$
}

\author{
CARMEN LÚCIA FERREIRA FAVA(2), ROSELI MUNIZ GIACHINI(2), JOSÉ LUIZ DA SILVA(3), \\ MÁRIO ZORTÉA ANTUNES JÚNIOR ${ }^{(4)}$ e TONNY JOSÉ ARAÚJO DA SILVA ${ }^{(5)}$
}

\begin{abstract}
RESUMO
O objetivo deste trabalho foi avaliar a influência da radiação solar em ambientes protegidos para produção inicial de hastes florais de Strelitzia reginae. Foram empregadas quatro condições de sombreamento e uma testemunha a pleno sol. As variáveis analisadas foram número, altura, diâmetro, massa fresca de hastes florais e comprimentos de inflorescências. A produção foi maior em pleno sol, com 37 hastes e massa fresca média de 100,2 g, seguido pelo ambiente A3, com 24 hastes e massa média que não diferiu significativamente do anterior e A5 apresentou 18 hastes, com as variáveis similares aos ambientes anteriores, porém com massa fresca $(79,74 \mathrm{~g})$ e diâmetros inferiores aos demais ambientes, enquanto os ambientes A2 e A4 não tiveram produtividade. O número, altura, diâmetro e massa fresca das hastes, atingem seus maiores valores em ambientes com até $30 \%$ de sombreamento e, em condições onde a luz é limitada, há atraso na produção inicial de hastes. A radiação assegura o processo produtivo, porém quando incide diretamente sobre a planta, aliada a outros fatores ambientais como temperatura e umidade relativa do ar, comprometem o padrão comercial da cultura. Palavras-chave: flor tropical, ave-do-paraíso, radiação solar global, radiação fotossinteticamente ativa.
\end{abstract}

\begin{abstract}
Shading in the initial production of flower stalks of Strelitzia reginae in Acorizal, MT

The aim of this study was to evaluate the solar radiation effect in greenhouses for initial production of flower stalks of Strelitzia reginae. We evaluated number, height, diameter and fresh weight of buds and inflorescence lengths. The yield was higher in full sun, with 37 flower stalks and fresh weight of $100.2 \mathrm{~g}$, followed by A3 environmental, with 24 rods and medium weight which did not differ significantly from the previous 18 and A5 showed rods with variables similar to previous environments, but with fresh weight $(79.74 \mathrm{~g})$ and diameters inferior to the other environments, while the A2 and A4 environments did not yield. The number, height, diameter and fresh weight of stems, reaching its highest values in environments with up to $30 \%$ shade and in conditions where light is limited, there is delay in the initial production of flower stalks. The radiation ensures the production process, but when it focuses directly on the plant, combined with other environmental factors like temperature and relative humidity, affects the pattern of trade of culture.
\end{abstract}

Keywords: tropical flower, bird of paradise, global solar radiation, photosynthetically active radiation.

\section{INTRODUÇÃO}

A floricultura é um dos segmentos da agricultura de maior rentabilidade por unidade de área e proporciona um rápido retorno dos investimentos aplicados. O setor é altamente competitivo, exige a utilização de tecnologias avançadas e eficiência de distribuição e comercialização. Neste contexto, o Brasil se destaca pela expansão do cultivo de flores e folhagens tropicais, tanto para corte, quanto para produção de mudas (CASTRO, 2009).

O cultivo comercial de flores tropicais no país ainda é recente, com aproximadamente 269,5 ha de área plantada com flores de corte, das quais 246,6 ha em campo; 8,8 ha em estufa e 14,0 ha em telados. As principais espécies cultivadas são: helicônias (101,8 ha), estrelícia (65,4 ha), alpínias (51,7 ha) e gengibre ornamental (6,0 ha) (IBRAFLOR, 2002).
Strelitzia sp. tem recebido destaque na produção por sua beleza peculiar e exuberância por possuir vida útil em torno de 20 anos, florescer o ano todo com picos de produção para diferentes regiões e as inflorescências possuírem alto valor comercial com durabilidade variável (MURILLO, 2005; MACNISH, 2010), ter com vida útil que pode variar de 16,6 (BAYOGAN et al., 2008) a 30 dias ou mais (MURILLO, 2005), de acordo com as condições de cultivo, período de colheita e práticas adotadas em pós-colheita.

A criação de condições microclimáticas adequadas para as culturas no interior dos ambientes protegidos pode ser obtida por meio de diversas técnicas, em que as mais econômicas são aquelas nas quais se empregam o uso e a combinação de diferentes tipos de materiais de cobertura (GUISELINI et al., 2010).

Um fator fundamental para o desenvolvimento das plantas e a produção de flores é a radiação solar,

\footnotetext{
(1) Trabalho recebido para publicação em 28/05/2012 e aprovado em 26/02/2015

(2)Universidade Federal de Mato Grosso (UFMT), Faculdade de Agronomia, Medicina Veterinária e Zootecnia. Cuiabá-MT. *Autor correspondente:

clfava@superig.com.br

${ }^{(3)}$ Instituto Federal de Mato Grosso (IFMT), Campus de Campo Novo do Parecis - MT

${ }^{(4)}$ UNIVAG Centro Universitário, Várzea Grande-MT. Cep 78118-000

${ }^{(5)}$ Universidade Federal de Mato Grosso (UFMT), Campus Universitário de Rondonópolis, Rondonópolis-MT.
} 
caracterizada por sua qualidade, duração e intensidade, uma vez que varia de acordo com a latitude do local, com as condições atmosféricas e posicionamento do sol ao longo do dia (SILVA et al., 2012). Por outro lado, a transmissividade do material de cobertura à radiação solar depende de suas características químicas e físicas, condições atmosféricas, ângulo de incidência dos raios solares, condensação no interior da superfície de cobertura, tempo de exposição às condições ambientais e deposição de partículas sólidas, como poeira e fuligem (TULLER e PETERSON, 1988) tornam imprescindíveis o monitoramento da sua variação espacial e temporal.

Ademais, a qualidade da luz está associada à composição do seu espectro, ou seja, à participação dos diferentes comprimentos de ondas, com elevada importância na produtividade, além de que outros processos relacionados à planta e ao ambiente dependem dessa fonte de energia, tais como a transferência de água da superfície para a atmosfera, o aquecimento e resfriamento do ar e do solo, assim como o processo de evapotranspiração (HELDWEIN et al., 2012).

Embora a temperatura e o fotoperíodo sejam os principais fatores que atuam na mudança de estado vegetativo para o reprodutivo, para algumas espécies, pode definir época de floração, enquanto a intensidade de luz afeta a fotossíntese, podendo vir a limitar ou otimizar o desenvolvimento da planta e a produção de flores (RADIN et al., 2003; KUNZ et al., 2007).

Pelo interesse crescente na produção de flores tropicais, existe atualmente uma grande demanda por informações sobre o seu cultivo, nas mais diferentes regiões produtoras, sendo necessárias pesquisas para a definição de parâmetros de produção. Conhecer essas exigências é fundamental, porque o sucesso da produção destas espécies também está relacionado a este fator. Estudos nesse sentido auxiliam a tomada de decisão do produtor em adequar ou não suas estruturas produtivas, visando ao manejo que possibilite a maximização da produção.

O presente trabalho teve por objetivo avaliar a influência da radiação solar em ambientes protegidos, para produção inicial de hastes florais de Strelitzia reginae.

\section{MATERIAL E MÉTODOS}

Apesquisa foi realizada na área experimental da Empresa Mato-grossense de Pesquisa, Assistência e Extensão Rural (EMPAER-MT), no município de Acorizal, Estado de Mato Grosso (22॰42’40” S, 47³7’30” W e altitude de 546 m). O clima da região, segundo a classificação de Köppen, é AW, denominado tropical úmido com seca no inverno (PEREIRA et al., 2002).

A área destinada ao experimento foi arada, gradeada e o $\mathrm{pH}$ corrigido com calcário dolomítico com base na análise de solo, em quantidade suficiente para elevar a saturação por bases à $60 \%$.

Foram utilizados cinco tratamentos, sendo a testemunha em ambiente a pleno sol (A1) e os demais tratamentos foram instalados em estrutura metálica cobertas com telas de sombreamento, de acordo com os tratamentos em área individual de $80 \mathrm{~m}^{2}(8 \mathrm{~m} \mathrm{x} 10 \mathrm{~m})$ : sob telado com sombreamento de $50 \%$ mais filme de $150 \mu$ (A2); sob telado com sombreamento de $30 \%$ mais filme de $150 \mu$ (A3); $50 \%$ de sombreamento (A4) e com $30 \%$ de sombreamento (A5).

As covas foram previamente preparadas nas dimensões $0,30 \mathrm{~m} \times 0,30 \mathrm{~m} \times 0,30 \mathrm{~m}$, com espaçamento de $1 \mathrm{~m} \times 1 \mathrm{~m}$, totalizando 48 covas para cada ambiente.

$\mathrm{Na}$ adubação de plantio, foram incorporados em cada cova 5 L de adubo orgânico (esterco bovino) e $100 \mathrm{~g}$ de super simples, contendo $20 \%$ de $\mathrm{P}_{2} \mathrm{O}_{5}$. A adubação de desenvolvimento e produção (cobertura) foi realizada mensalmente, com $50 \mathrm{~g}$ de NPK (10:10:10) e 2 L de esterco bovino, a cada 90 dias.

As mudas utilizadas foram adquiridas de produtores reconhecidos e com certificado fitossanitário (livres de pragas e doenças), com idade de um ano e meio, medindo $0,5 \mathrm{~m}$ de altura. $\mathrm{O}$ plantio foi mantido sob regime de irrigação, no sistema de micro-aspersão, com a finalidade de suprir as necessidades hídricas da cultura.

Em cada ambiente foi instalado um termo-higrômetro e as leituras diárias dos dados de temperatura e umidade relativa registradas em planilhas.

Os valores instantâneos das leituras foram realizados a cada minuto e as médias armazenadas em intervalos de cinco minutos. As medidas da radiação solar global (Qg) foram obtidas com auxílio do sensor piranômetro modelo LI-200X-L (LI-COR Biosciences Inc.) e da radiação fotossinteticamente ativa (PAR), sensor quantum modelo LI-190SB-L (LI-COR Biosciences Inc.). Foi utilizado o datalogger CR 1000 (Campbell Scientific Inc.) e os equipamentos foram alimentados com tensão de $12 \mathrm{~V}$ por uma bateria de $48 \mathrm{Ah}$. Todos os sensores de radiação foram instalados no centro do ambiente, juntamente com o termohigrômetro a 1,5 m de altura.

Os parâmetros para avaliação da produção foram número, altura, diâmetro e massa fresca das hastes florais.

A variação da radiação solar global foi avaliada em um dia de céu limpo a cada minuto por 12 horas e os dados representados graficamente. Enquanto as médias de produção foram submetidas à análise de variância e comparadas pelo teste de Scott-Knott $(\mathrm{p}<0,01)$.

\section{RESULTADOS E DISCUSSÃO}

Os valores da radiação solar global $(\mathrm{Qg})$ e da radiação fotossintética ativa medida indicaram maior transmitância no ambiente a pleno sol (A1) em relação às coberturas utilizadas nos outros ambientes. O ambiente com telas de sombreamento $50 \%$ mais filme teve menor medida de radiação solar global e PAR, seguido do ambiente com telas sombreamento $30 \%$ mais filme (A3) e telas de sombreamento $50 \%$ (A4) quando comparados com ambiente de telas de sombreamento 30\% (A5) (Figuras 1 e 2). 


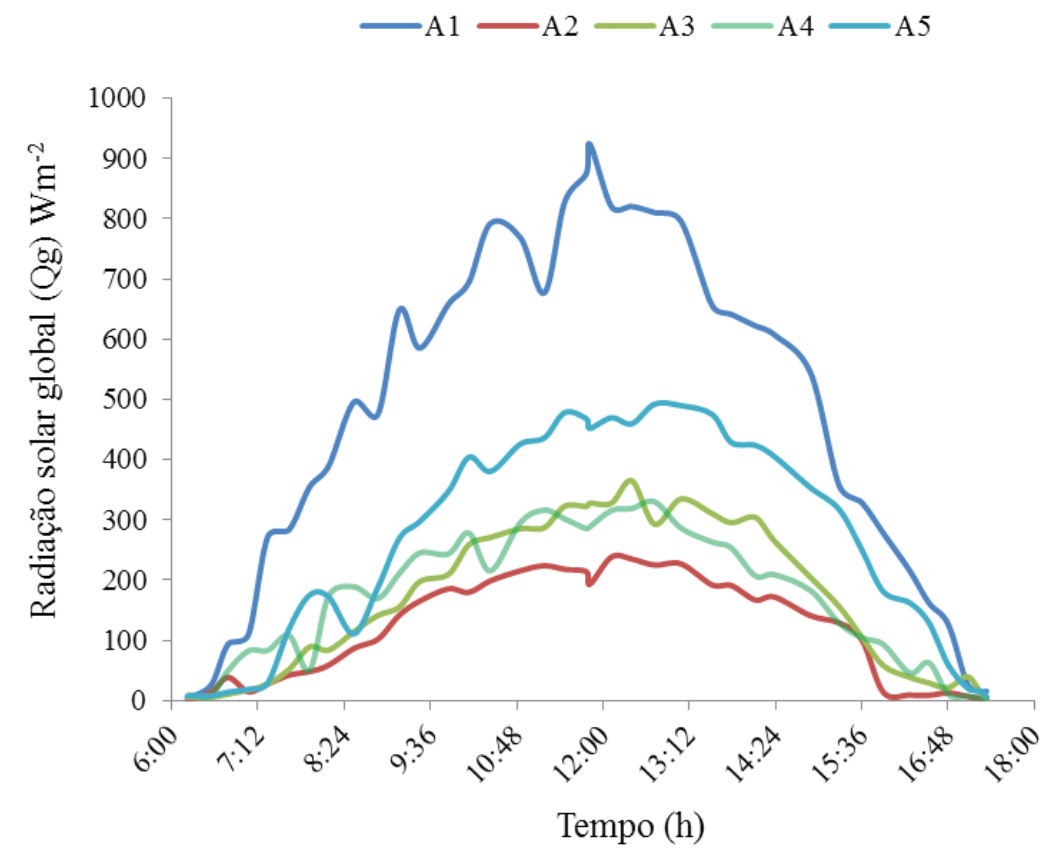

Figura 1. Variação horária da radiação solar global $(\mathrm{Qg})$ sobre a produção do $1^{\circ}$ ciclo de Strelitzia reginae em função dos ambientes de cultivo: A1 (pleno sol), A2 (50\% de sombreamento mais filme),

A3 (30\% de sombreamento mais filme), A4 (50\% de sombreamento) e A5 (30\% de sombreamento).

Figure 1. Hourly variation of solar radiation $(Q g)$ on the production of a cycle of Strelitzia reginae as a function of environmental conditions: A1 (full sun), A2 (50\% shading more film), A3 (30\% shading more film) A4 (50\% shading) and A5 (30\% shading).

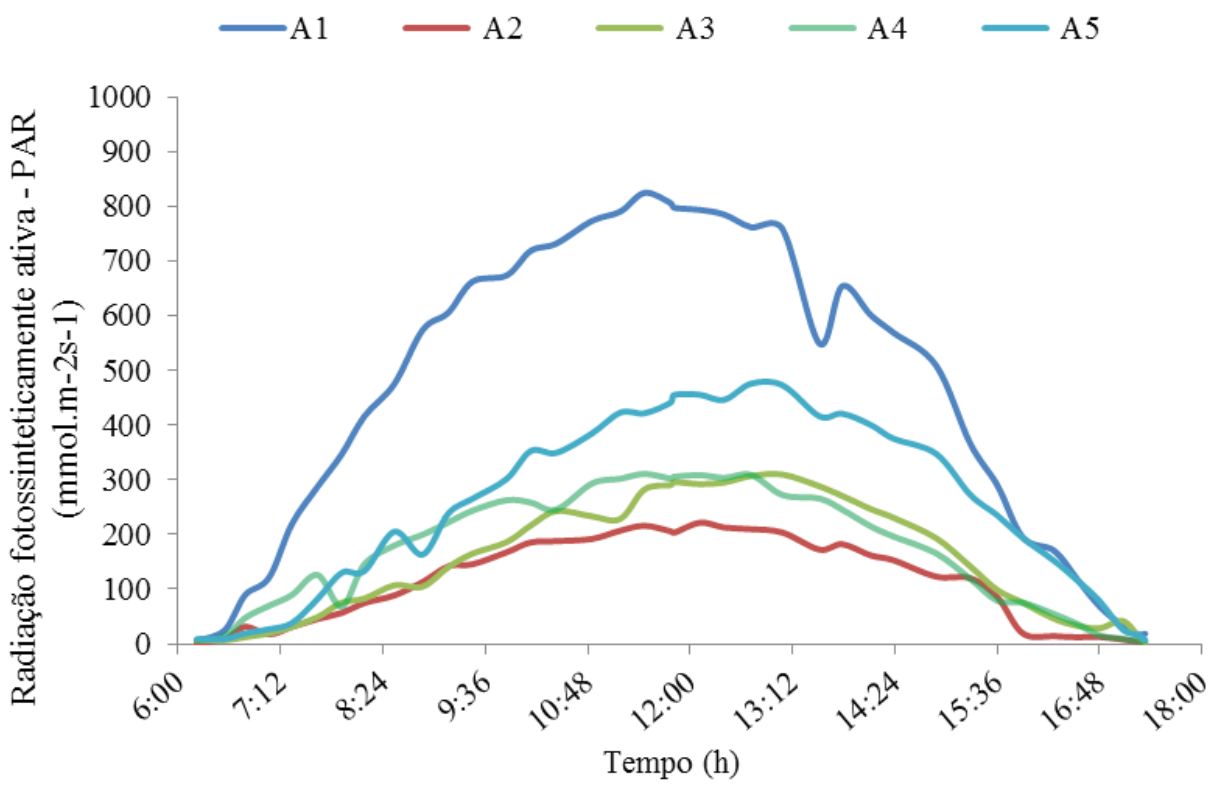

Figura 2. Variação horária da radiação fotossinteticamente ativa (PAR) sobre a produção do $1^{\circ}$ ciclo de Strelitzia reginae em função dos ambientes de cultivo: A1 (pleno sol), A2 (50\% de sombreamento mais filme), A3 (30\% de sombreamento mais filme), A4 (50\% de sombreamento) e A5 (30\% de sombreamento).

Figure 2. Time variation of photosynthetically active radiation (PAR) on the production of a cycle of Strelitzia reginae as a function of environmental conditions: A1 (full sun), A2 (50\% shading more film), A3 (30\% shading more film) A4 (50\% shading) and A5 (30\% shading). 
No ambiente A1, o valor máximo de radiação solar global foi $874,8 \mathrm{Wm}^{-2}$ com pleno desenvolvimento das plantas, enquanto o A2 atingiu $214 \mathrm{Wm}^{-2}$ influenciando a produção, não apresentando hastes florais quando comparados aos outros ambientes. Verificou-se que durante o dia o valor máximo de radiação solar global medido no ambiente foi de $238,3 \mathrm{Wm}^{-2}$ (Figura 3 ).
Os dados da radiação solar global $(\mathrm{Qg}) \mathrm{Wm}^{-2}$ e da transmitância (Tabela 1) indicam que os valores são sensivelmente menores no interior do ambiente A2, em comparação com o ambiente externo, o que se deve à reflexão e à absorção promovidas pela cobertura de filme de plástico, que diminui a incidência de radiação solar no interior do ambiente protegido (PEREIRA et al., 2002).

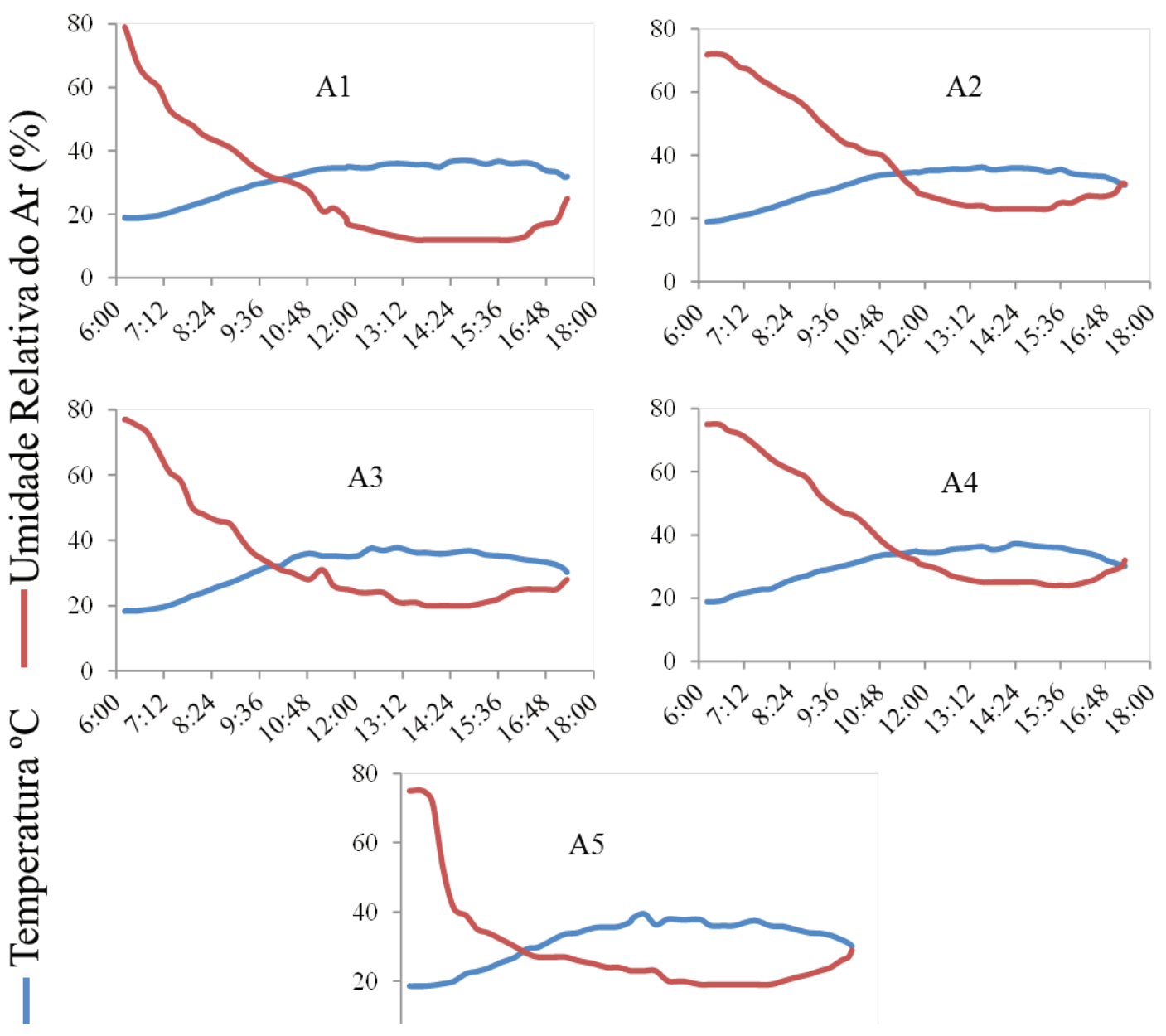

Figura 3. Variação horária da temperatura e umidade relativa nos ambientes de cultivo de Strelitzia reginae: pleno sol (A1), A2 (50\% de sombreamento mais filme), A3 (30\% de sombreamento mais filme), A4 (50\% de sombreamento) e A5 ( $30 \%$ de sombreamento).

Figure 3. Hourly variation of temperature and relative humidity in the environmental conditions of Strelitzia reginae: full sun (A1), A2 (50\% more shading film), A3 (30\% more shading film), A4 (50\% shading) and $A 5$ (30\% shading).

Tabela 1. Valores da radiação solar global (W m-2) e da transmitância das coberturas: $50 \%$ de sombreamento mais filme (A2); $30 \%$ de sombreamento mais filme (A3); $50 \%$ de sombreamento (A4) e 30\% de sombreamento (A5) em relação ao ambiente externo (A1)

Table 1. Values of global radiation ( $W \mathrm{~m}-2)$ and the transmittance of the coverage: $50 \%$ more shading film (A2), $30 \%$ more shading film (A3), 50\% shading (A4) and 30\% shading (A5) in relation to the outside (A1)

\begin{tabular}{|c|c|c|c|c|c|c|c|c|}
\hline \multicolumn{3}{|c|}{$\operatorname{Qg}\left(\mathrm{Wm}^{-2}\right)$} & \multicolumn{4}{|c|}{ Transmitâncias (\%) } \\
\hline A1 & A2 & A3 & A4 & A5 & A2 & A3 & A4 & A5 \\
\hline 874,8 & 214,0 & 322,3 & 285,4 & 468,0 & 24,46 & 36,84 & 32,62 & 53,49 \\
\hline
\end{tabular}


Verificou-se ainda que, entre os ambientes cobertos, há maior transmitância no A5 (Tabela 1) e para a produção de hastes florais foram encontrados valores similares deste ambiente com o A3.

Pelos resultados apresentados na produção inicial, após nove meses de plantio não houve desempenho superior dos ambientes sombreados em relação ao pleno sol, porém quando comparados pelo investimento das coberturas dos ambientes, não houve produção superior ao ambiente A1.

Os valores de temperatura $\left({ }^{\circ} \mathrm{C}\right)$ e umidade relativa do ar (\%) nos cinco ambientes estão apresentados na figura 3. Observa-se ao longo do dia que a umidade relativa foi mais baixa no ambiente A1 com 19\% em relação aos demais, entretanto a temperatura máxima registrada nesta condição foi de $36,9{ }^{\circ} \mathrm{C}$, inferior aos valores obtidos nos ambientes com telas sombreamento (A2 e A3), comprovando o efeito estufa, ou seja, a cobertura plástica permite a entrada de radiação solar de ondas curtas e dificulta a saída da radiação térmica (ondas longas) emitida pelas plantas e superfície do solo aquecido pelo sol.

A aplicação de diferentes condições de sombreamento resultou em efeitos significativos para algumas variáveis e para outras não. O número de hastes emitidas durante os nove meses foi sempre maior no ambiente A1 (37 hastes) quando comparados aos demais ambientes A3 e A5, com 24 e 18 hastes respectivamente, sendo que nos ambientes A2 e A4 não apresentaram hastes florais. Isto mostra o efeito positivo da intensidade de luz na emissão de hastes florais pela planta. As aves-do-paraíso que não recebem suficientemente uma quantidade de luz apresentaram baixa e até nula produtividade (MURILLO, 2005).

Cada haste, potencialmente, pode resultar em inflorescência comercial, é de se esperar que nessas condições do ambiente A1 também ocorra maior produção de flores, o que não garante a qualidade das hastes florais.

Aplicando-se análise de regressão entre o número de hastes e os níveis de sombreamento, percebeu-se a tendência de decréscimo no número de hastes dos ambientes sombreados (A3 e A5), quando comparados ao pleno sol (A1), com bom ajustamento dos pontos à linha (Figura 4). Nesta análise, foram desconsiderados os ambientes $\mathrm{A} 2$ e A4 pela falta de produção. Assim, o ambiente A1 seria o ponto ótimo para obtenção de maior número de hastes florais.
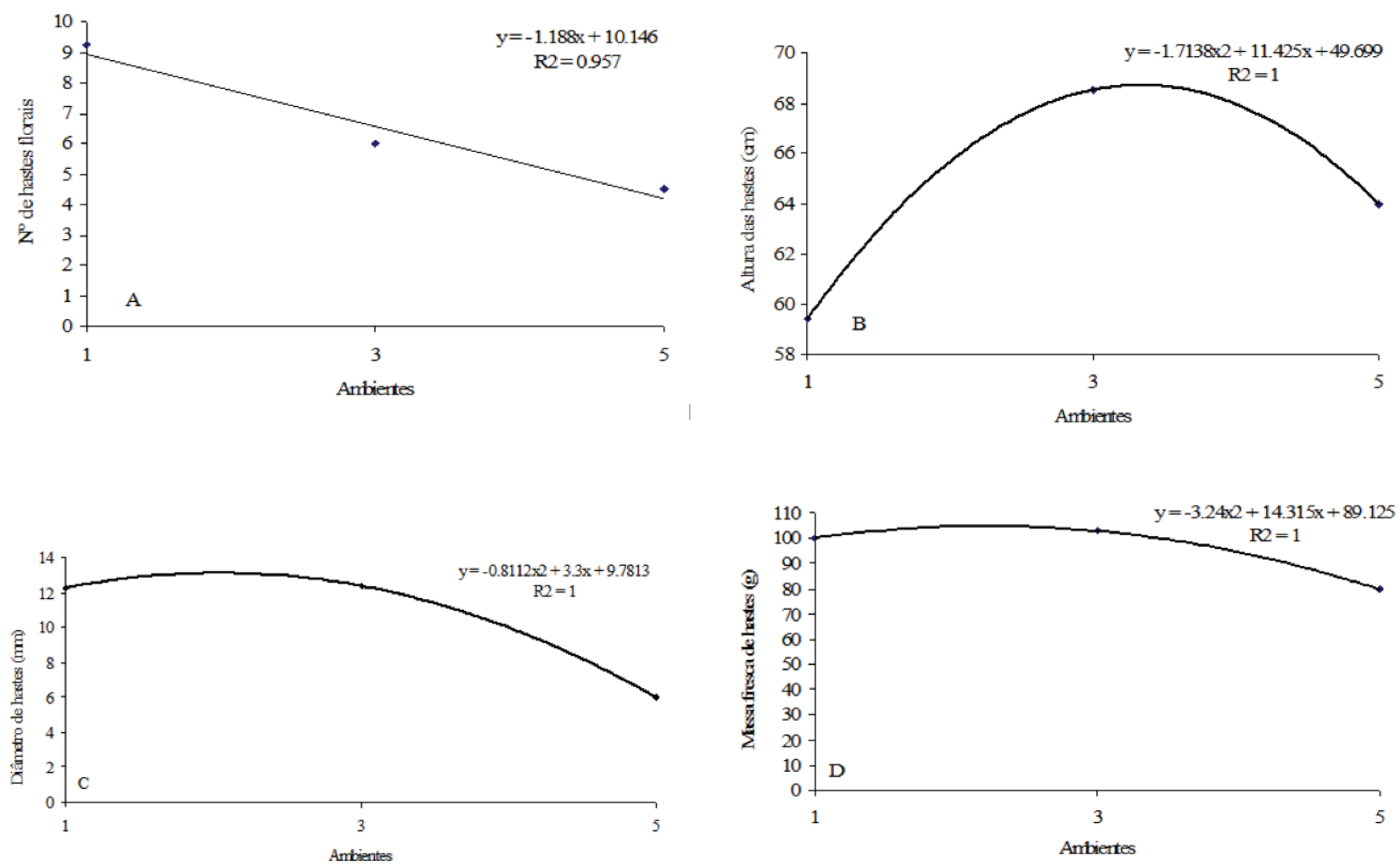

Figura 4. Efeito dos níveis de sombreamento sobre o número (A), altura (B), diâmetro (C) e massa fresca (D) de hastes de Strelitzia reginae, após nove meses do plantio nos ambientes: pleno sol (A1), $30 \%$ de sombreamento mais filme (A3) e $30 \%$ de sombreamento (A5).

Figure 4. Effect of shade levels on the number (A), height (B), diameter (C) and fresh weight (D) of stems of Strelitzia reginae, nine months after planting in full sun environments (A1), 30\% more shading film (A3) and 30\% shading (A5). 
A altura média das hastes florais apresentou diferença entre os sombreamentos, sendo superior em A1 e A3 (Figura 4B), que pode figurar uma característica positiva no processo de classificação, que segundo as informações do Centro de Comércio Internacional, a $S$. reginae é classificada pelo comprimento das hastes florais em: qualidade extra (Select) para hastes maiores de $90 \mathrm{~cm}$; qualidade 1 (Fancy) para hastes de 80 a $90 \mathrm{~cm}$; qualidade 2 (Standart) para hastes de 60 a $80 \mathrm{~cm}$ e qualidade 3 (Mini) para hastes de 40 a $50 \mathrm{~cm}$ (MURILLO, 2005). De acordo com essa classificação, as hastes do ambiente A1 e A5 estão classificadas com qualidade 3 e as hastes do ambiente A3 na qualidade 2 .

Percebe-se ainda uma tendência crescente da altura da haste floral nos ambientes A1 e A3, e decrescente atingindo níveis mais baixos no ambiente $\mathrm{A} 5$, o que pode ser explicado pela capacidade de produção da cultura em função da energia disponível no ambiente (FURLAN e FOLEGATTI, 2002). Logo, o ambiente em pleno sol oferece as melhores condições para o desenvolvimento de estrelícia.

Os ambientes A1 e A3 também sobressaíram na média dos diâmetros de hastes florais quando em comparação ao A5 (Figura 4C). Da mesma forma, constatou-se que à medida que aumenta o sombreamento diminui o peso de massa fresca acumulada (Figura 4D) das hastes nos ambientes A1 e A3 (100,2 g e 102,9 g, respectivamente). Os valores de peso de massa fresca total no ambiente A3 $(102,9 \mathrm{~g})$ podem estar relacionados com o filme utilizado, pois deixa o ambiente mais úmido (Tabela 2).

O maior valor de peso de massa fresca, nos ambientes A1 e A3, provavelmente não está associado só à radiação solar, mas a uma condição microclimática diferenciada.

Visualmente, as plantas que se encontravam nos ambientes A1 apresentavam queimaduras nas bordas foliares, sendo que no A3 a intensidade foi menor. No cultivo do ambiente A1 as folhas apresentavam amarelecimento, provavelmente esse efeito deve estar mais associado ao excesso de radiação do que deficiências nutricionais, já que esse sintoma não apareceu nos demais ambientes (A3 e A5). Os ambientes A2 e A4 apresentaram visualmente efeito no desenvolvimento, com plantas menos volumosas, menor crescimento e reduzido número de folhas.

Apesar do controle local de pragas, a menor incidência de radiação solar no ambiente $\mathrm{A} 2$, aliada a alta umidade, favoreceu a presença de cochonilhas (Dysmicoccus sp.), insetos que causam danos diretos ao sugar continuamente a seiva provocando manchas, definhamento até sua morte $\mathrm{e}$, indiretamente, contribuem para o desenvolvimento da fumagina (Capnodium sp.) nas folhas de algumas plantas, o que pode comprometer o padrão comercial das hastes florais, pelo amarelecimento e queda das folhas em mais de $50 \%$ dos casos (MATTIUZ et al., 2006).

Adicionalmente, Radin et al. (2003) verificaram que para um mesmo valor de radiação fotossinteticamente ativa interceptada, se obtém maior eficiência de uso da radiação pelo tomateiro quando cultivado em estufa do que a céu aberto. Enquanto Pezzopane et al. (2004) concluíram que fatores como latitude local, época do ano e horário do dia controlam a atenuação da radiação solar pela tela plástica. Acrescentando que isso é importante, pois a recomendação sobre densidade ideal de tela para o cultivo de uma determinada espécie pode ser diferente de uma região para outra.

Steidle Neto et al. (2006) relataram que a relação RFA/Rg é susceptível às distintas condições atmosféricas predominantes nos períodos secos e chuvosos, sendo maior durante os meses com precipitação elevada e menor nos meses com alta estiagem, evidenciando existir variabilidade sazonal desta relação.

Tabela 2. Efeito dos níveis de sombreamento na média de produção inicial sobre o número (NHF), altura (AHF), diâmetro (DHF) e massa fresca (MFHF) de hastes de Strelitzia reginae, após nove meses do plantio

Table 2. Effect of shade levels on average initial production on the number (NHF), height (AHF), diameter (DHF) and fresh (MFHF) of stems of Strelitzia reginae, nine months after planting

\begin{tabular}{|c|c|c|c|c|}
\hline Ambiente & NHF & AHF (cm) & DHF (mm) & MFHF (g) \\
\hline A1 & 37 & $59,41 \mathrm{~b}$ & $12,27 \mathrm{a}$ & $100,20 \mathrm{a}$ \\
\hline A2 & 0 & $0,00 \mathrm{c}$ & $0,00 \mathrm{~b}$ & $0,00 \mathrm{c}$ \\
\hline A3 & 24 & $68,55 \mathrm{a}$ & $12,38 \mathrm{a}$ & $102,91 \mathrm{a}$ \\
\hline A4 & 0 & $0,00 \mathrm{c}$ & $0,00 \mathrm{~b}$ & $0,00 \mathrm{c}$ \\
\hline A5 & 18 & $56,04 \mathrm{~b}$ & $6,00 \mathrm{a}$ & $79,74 \mathrm{~b}$ \\
\hline
\end{tabular}

Médias seguidas de mesma letra, na coluna, não diferem significativamente pelo teste de $\operatorname{Scott-Knott~}(p>0,1)$ 


\section{CONCLUSÕES}

O desenvolvimento de $S$. reginae apresenta maiores valores em ambiente com até $30 \%$ de sombreamento. Em condições onde a luz é limitada, há atraso na produção de hastes florais.

A radiação assegura o processo produtivo, mas quando incide diretamente sobre a planta, aliada à alta temperatura e à baixa umidade relativa do ar, compromete o padrão comercial.

\section{REFERÊNCIAS}

CASTRO, C.F. História da floricultura brasileira: organização e evolução. Magistra, Cruz das Almas, v.21, n.4, p.233-252, 2009.

BAYOGAN, E.R.V.; JAROENKIT, T.; PAULL, R.E. Postharvest life of Bird-of-Paradise inflorescences. Postharvest Biology and Technology, v.48, p.259-263, 2008.

FURLAN, R.A; FOLEGATTI, M.V. Distribuição vertical e horizontal de temperaturas do ar em ambientes protegidos. Revista Brasileira de Engenharia Agrícola e Ambiental, Campina Grande, v.6, p.93-100, 2002.

GUISELINI, C.; SENTELHAS, P.C.; PANDORFI, H.; HOLCMAN, E. Manejo da cobertura de ambientes protegidos: Radiação solar e seus efeitos na produção da gérbera. Revista Brasileira de Engenharia Agrícola e Ambiental, Campina Grande, v.14, p.645-652, 2010.

HELDWEIN, A.B.; MALDANER, I.C.; RADONS, S.; LOOSE, L.H.; LUCAS, D.D.P.; HINNAH, F.D. Estimativa do saldo de radiação em girassol como função da radiação solar global. Revista Brasileira de Engenharia Agrícola e Ambiental, Campina Grande, v.16, p.194-199, 2012.

IBRAFLOR. Levantamento Ibraflor: Banco de Dados. São Paulo: 2002.

KUNZ, J.H.; BERGONCI, J.I.; BERGAMASCHI, H.; DALMAGO, G.A.; HECKLER, B.M.M.; COMIRAN, F. Uso da radiação solar pelo milho sob diferentes preparos do solo, espaçamento e disponibilidade hídrica. Pesquisa Agropecuária Brasileira, Brasília, v.42, p.1511-1520, 2007.
MACNISH, A.J.; REID, M.S.; MARRERO, A.; JIANG, C.Z. Improving the postharvest performance of bird-ofparadise flowers. Acta Horticulturae, Leuven, v.877, p.1763-1770, 2010.

MATTIUZ, C.F.M.; CAMPOS, L.Z.O.; PINTO, A.S. Levantamento de plantas ornamentais e cochonilhas (Insecta, Hemiptera) associadas em residências de Ribeirão Preto, SP. Revista Brasileira de Horticultura Ornamental, Campinas, v.12, p.43-51, 2006.

MURILLO, G. Técnicas de produção da planta ave-doparaíso: Strelitzia reginae. Cuiabá: SEBRAE, 2005. 56p.

PEREIRA, A.R.; ANGELOCCI, L.R.; SENTELHAS, P.C. Agrometeorologia: Fundamentos e aplicações práticas. Guaíba: Agropecuária, 2002. 478p.

PEZZOPANE, J.E.M.; OLIVEIRA, P.C.; REIS, E.F.; LIMA, J.S.S. Alterações microclimáticas causadas pelo uso de tela plástica. Engenharia Agrícola, Botucatu, v.24, p.9-15, 2004.

RADIN, B.; BERGAMASCHI, H.; REISSER JUNIOR, C.; BARNI, N.A.; MATZENAUE, R.; DIDONÉ, I.A. Eficiência de uso da radiação fotossinteticamente ativa pela cultura do tomateiro em diferentes ambientes. Pesquisa Agropecuária Brasileira, Brasília, v.38, p.1017-1023, 2003.

SILVA, C.R.; SILVA, V.J.; ALVES JUNIOR, J.; CARVALHO, H.P. Radiação solar estimada com base na temperatura do ar para três regiões de Minas Gerais. Revista Brasileira de Engenharia Agrícola e Ambiental, Campina Grande, v.16, p.281-288, 2012.

STEIDLE NETO, A.J.; RIBEIRO, A.; ZOLNIER, S.; LEITE, F.P. Variabilidade sazonal da relação entre a radiação fotossinteticamente ativa e a radiação global na bacia do rio Doce, Estado de Minas Gerais. Acta Scientiarum Agronomy, Maringá, v.28, p.429-435, 2006.

TULLER, S.E.; PETERSON, M.J. The solar radiation environment of greenhouse grown Douglas-fir seedlings. Agricultural and Forest Meteorology, v.44, p.49-65, 1988. 
